\title{
FACTORS AFFECTING CLOUD COMPUTING ADOPTION AMONG UNIVERSITIES AND COLLEGES IN THE UNITED STATES AND CANADA
}

\author{
William Klug, British Columbia Institute of Technology, bklug@bcit.ca \\ Xue Bai, Virginia State University, xbai@vsu.edu
}

\begin{abstract}
Many colleges and universities around the world are adopting cloud computing resources and services. The benefits of cloud computing for institutions and students include factors such as mobility, scalability, security, availability, interoperability, and end user satisfaction in the use of software applications and other computing resources. However, some institutions are not taking advantage of the services offered by the cloud computing paradigm. Using the technology-organization-environment (TOE) framework, the authors have proposed a research model to investigate the factors that determine the adoption of cloud computing by colleges and universities. A nonexperimental, cross-sectional, quantitative study was conducted in 2013 of 119 CIOs and IT managers in colleges and universities in the U.S. and Canada that have implemented, or were planning to implement, cloud computing environments. An online survey was used to gather data to test the relationship between the criterion variable (cloud computing adoption) and the predictor variables (relative advantage, complexity, compatibility, institutional size, technology readiness, perceived barriers, regulatory policy, and service provider support). The results of the logistic regression analysis indicated that complexity, institutional size, and technology readiness were statistically significant in determining cloud computing adoption. The predictor variables relative advantage, regulatory policy, and service provider support were not statistically significant.
\end{abstract}

Keywords: Cloud Computing, Technology Adoption, Technology-Organization-Environment Framework, College and University

\section{INTRODUCTION}

Cloud computing is "a new dawn" for education [49]. Cloud computing is enabling students, researchers, lecturers, and administrative staff at colleges and universities to access services provided by new computing paradigms, including Infrastructure as a Service (IaaS), Platform as a Service (PaaS), and Software as a Service (SaaS) [49].

Cloud computing virtualizes resources, such as software applications and labs, allowing them to be delivered over the Internet instead of being installed on school workstations and student computers [60]. As such, cloud computing has become an important enabler of distance and online education programs, e-learning systems, and mobile learning [3, 4, 14, 24, 37, 40, 59].

Institutions are implementing one of three different cloud computing models. First, colleges have created their own cloud computing environments or private clouds $[16,44]$. Second, colleges have formed consortiums with other institutions to build cloud computing infrastructures [12] and governments are investing in shared cloud infrastructures for universities [20]. Third, universities are purchasing cloud computing services from third parties [30].

The problem that was researched in this study was the lack of understanding of the factors that determine cloud computing adoption by some colleges and universities and not by others. Cloud computing has been adopted by firms, businesses, industries and government agencies [10, 15, 19, 21, 28, 25, 41, 42, 48, 57]. Cloud computing adoption from the perspective of the user has been studied both in post-secondary education and firms $[5,8,24,26$, $34,38,41]$. However, the factors that determine the cloud computing adoption by colleges and universities had not been investigated. 


\section{LITERATURE REVIEW}

Cloud computing is increasing in its use and importance in colleges and universities in the U.S., Europe and Australia $[3,4,7,12,14,18,25,41,43,44,46,49,58]$. Governments are funding cloud computing initiatives in higher education institutions [16, 20], colleges and universities are purchasing cloud resources from third party service providers $[18,30]$, and colleges and universities are developing their own internal, proprietary cloud computing environments $[6,12,16,25,44,45]$.

There is research to support the authors' link between cloud computing and colleges and universities. Cloud computing has been adopted and used, at the individual level, by students in post-secondary institutions $[1,5,9,13$, 49, 51, 52, 56]. Using the Technology Acceptance Model 3, researchers have shown that community college students have adopted cloud computing technology [5]. Cost effectiveness goes 'hand-in-hand' with how well cloud computing fits in an organization [5]. Although the levels of acceptance and understanding of cloud computing by teachers was not studied, teachers did show "clear differences" when interviewed [5]. The study of cloud computing adoption among community college students is important because the students were enrolled in an online, introductory course in computing using a virtual desktop that was hosted by the Virtual Computing Lab (VCL), a proprietary cloud computing environment, at North Carolina State University (NCSU). The VCL at NCSU has been studied extensively [44, 60].

Colleges and universities are migrating to cloud computing environments for a variety of reasons [49], particularly economic [17, 31]. From an educational point of view, the cloud is a balance between control and economy of scale, offering a lower total cost of ownership model [23]. "Cloud computing is attractive to small and mediumsized educational institutions" [23].

The main advantage of cloud computing is cost effectiveness in the implementation of hardware and software [37]. Cloud computing can be used to develop quality, low cost education on a global basis [37]. Relying on single machines for computing can no longer be financially justified [36]. There are iterative benefits of connecting universities through the infrastructure of the cloud [36]. There are also efficiencies to be gained in aggregating IT services, including personnel, licensing, expertise, and business continuity [47].

The pressure to reduce costs and rapid advances in technology are compelling arguments for cloud computing adoption by colleges and universities [49]. Cloud computing improves efficiency, cuts costs, and is convenient for the educational sector [49]. The commoditization of IT services and the pay-as-you-go nature of cloud computing influence the financial decisions related to IT spending [49]. Cloud computing involves a paradigm shift for university IT departments [49].

Cloud computing is becoming increasing associated with e-learning systems in colleges and universities. In the past, traditional e-learning systems were internal to higher education institutions [24]. However, exterior, cloudbased e-learning is now feasible for institutions, creating efficiencies in investments and power management [24]. Cloud computing is a low cost computing solution for researchers, faculty and students at academic institutions [2, 4]. Cloud computing can be used to build virtual computing environments, particularly in the areas of science education and distance or online education [4].

\section{RESEARCH MODEL AND HYPOTHESES}

The TOE framework, developed by Tornatzky and Fleischer [54], was the research model used to study cloud computing adoption by firms [28]. The TOE framework has been used by other researchers to analyse the adoption of a variety of information systems (IS) and technical innovations, including c-commerce, online retailing, ebusiness, and ERP $[11,27,32,33,53,61]$. The TOE framework has also been shown to be consistent with Rogers' [39] diffusion of innovations theory because both theories share constructs related to innovation adoption [11, 27, $28,33,53]$.

The TOE framework is used by researchers to study the adoption and implementation of technological innovation by firms [54]. The model includes three main elements: the technological context, the organizational context, and the environmental context [54]. The technology element includes the availability and characteristics of the technology 
[54]. The organization element looks at formal and informal linking structures, communication processes, size, and slack [54]. The external task environment element examines industry characteristics and market structure, technology support infrastructure, and government regulation [54].

The authors' proposed model has been adopted and modified from Low, Chen and $\mathrm{Wu}$ [28]. The theoretical model is based on the TOE framework. The proposed model includes the variables of relative advantage, complexity, and compatibility as part of the technology context; the variables institutional size, technology readiness, and perceived barriers as part of the organization context; and the variables regulatory policy and service provider support as part of the environmental context. The authors' research model is shown in Figure. 1.

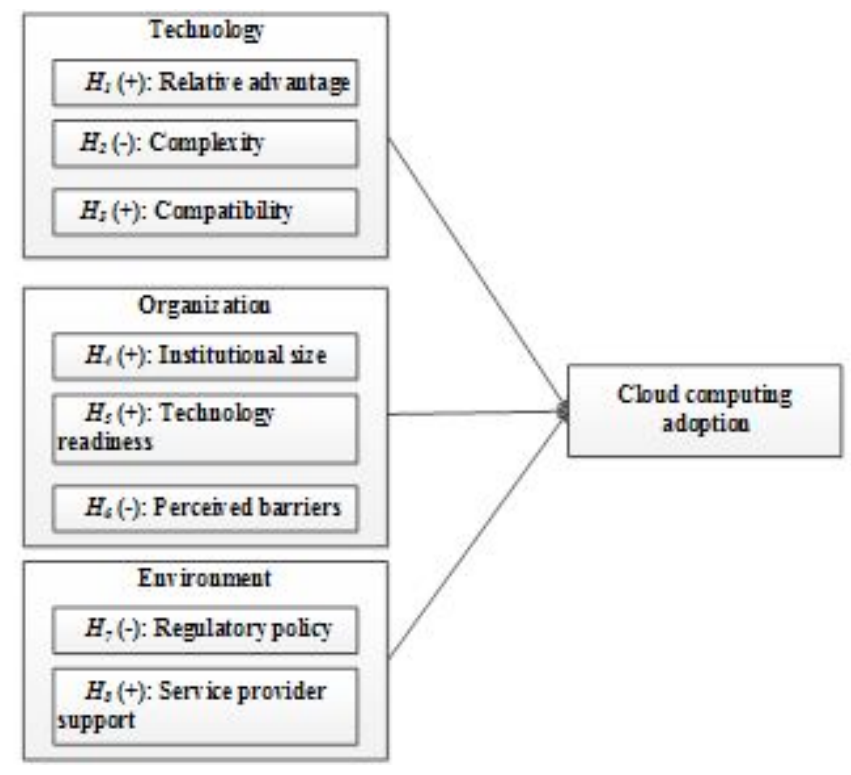

Figure 1. Research Model

Adapted from "Understanding the Determinants of Cloud Computing Adoption," by C. Low, Y. Chen, and M. Wu, 2011, Industrial Management + Data Systems, 111(7), p. 1011. Copyright 2011 by the Emeral Group Publishing Limited.

Adapted with permission.

In an analysis of studies of innovation adoption, the innovation characteristics that had the most significant influence on innovation adoption were relative advantage, complexity, and compatibility [55]. Relative advantage refers to the perception that adoption of an innovation will be advantageous to the firm [39]. Complexity is the perceived difficulty by a firm to understand and use an innovation [39]. The compatibility of innovation is the degree to which the innovation is consistent with the values, past experiences, and needs of the adopter [39]. Institutional size has two factors: the number of employees and annual revenue [28, 33, 61]. Technology readiness has two factors: IT infrastructure and IT human resources [28, 32,33]. Perceived barriers to the adoption of an innovation range from the suitability of the innovation to the business, to the lack of security [50]. Obstacles can also range from firm size to legal issues [32]. Regulatory policy issues range from government tax policies [33] to security and privacy concerns [49]. Colleges and universities are purchasing cloud computing services at reduced costs [44]. They also receive cloud computing services for free [47,49]. Service level or support agreements with cloud computing service providers have a direct impact on a school's decision to adapt cloud computing [22].

The following set of hypotheses was derived from a review of the literature on cloud computing adoption. The hypotheses are numbered to correspond to the labels shown in Figure 1. The anticipated effect each predictor variable would have on the criterion variable is shown as a plus sign (positive effect) or minus sign (negative effect) enclosed parentheses. The hypotheses were used to test the research model involving the technology context, organizational context, environmental context, and cloud computing adoption. 
$\mathrm{H}_{1}$ : Relative advantage is positively associated with cloud computing adoption.

$\mathrm{H}_{2}$ : Technical complexity is negatively associated with cloud computing adoption.

$\mathrm{H}_{3}$ : Technical compatibility is positively associated with cloud computing adoption.

$\mathrm{H}_{4}$ : Institutional size is positively associated with cloud computing adoption.

$\mathrm{H}_{5}$ : Technology readiness is positively associated with cloud computing adoption.

$\mathrm{H}_{6}$ : Perceived barriers are negatively associated with cloud computing adoption.

$\mathrm{H}_{7}$ : Regulatory policy is negatively associated with cloud computing adoption.

$\mathrm{H}_{8}$ : Service provider support is positively associated with cloud computing adoption.

\section{METHODOLOGY}

\section{Sampling and Instrument}

The authors collected data using an online survey. A link to the online survey was contained in an individual e-mail sent to each potential respondent. E-mail addresses and other personal contact information were obtained from a list of CIOs, IT managers, and IS managers of two-year and four-year colleges and universities in the U.S. and Canada. The custom-targeted mailing list was purchased from Prepackaged Marketing Data. The validation of the data contained in the mailing list resulted in a total of 71 individuals at Canadian institutions and 1,596 individuals at U.S. institutions being selected to participate in the study. In addition, the Canadian University Council of Chief Information Officers (CUCCIO) solicited their 53 members to participate in the survey.

The survey consisted of 42 items. Eleven items were used to collect demographic data. The remaining 31 items were used to evaluate the eight predictors in the research model. Survey items were based on questionnaires from literature reviews (sources), and adapted and modified to fit the context of this study.

\section{Survey Results}

The authors received 163 responses to the survey. Forty-two responses were rejected because they contained missing responses to items measuring the predictor variables. Two responses were identified as outliers and were also rejected. A total of 119 responses were used in the analysis. The overall response rate was $9.5 \%(163 / 1,720)$ and the valid response rate was $6.9 \%(119 / 1,720)$.

The data analysis for this study was conducted in two stages. In the first stage, a factor analysis was conducted to identify the inter-correlations of the predicator variables. The first stage also contained an assessment of the reliability and validity of the measurement items associated with the various factors. The second stage of the data analysis consisted of a logistic regression analysis to evaluate the relationship between the predictor variables and the criterion variable. The results of the regression analysis were used to test support for the hypotheses proposed in the research model.

\section{Factor Analysis and Scale Reliability}

A total of 31 items were developed to measure the eight factors in the theoretical model. A seven-point Likert scale was used in 29 of the items. Two items were measured using closed-ended, four-point ratio scales. The construct validity of the measurement items was determined by conducting a principal component analysis (PCA) with varimax rotation. A minimum loading value of 0.5 was used for all primary factor loadings with no cross-loadings. Thirteen items were eliminated because of cross-loading or their factor loadings were below the 0.5 threshold value. The dichotomous criterion variable, adoption, measured whether a college or university was an adopter or non- 
adopter of cloud computing. The criterion variable was operationalized by means of a "Yes" or "No" response to the question "Has your institution adopted cloud computing?"

The resulting factor analysis identified six factors that support the theoretical model. The six factors had eigenvalues greater than one and they explained $79.6 \%$ of the variance among the predicator variables. The KaiserMeyer-Olkin (KMO) measure of sampling adequacy was 0.761 , which is above the acceptable limit of 0.5 .

The KMO values for individual variables were also found to be acceptable. Bartlett's test of sphericity (correlation among the variables) was significant at $p<0.001$. This means the correlations between items were sufficient for PCA. The six factors were as follows: relative advantage (RA), technical complexity (CX), technology readiness (TR), institutional size (SZ), regulatory policy (RP), and service provider support (VS).

The means and standard deviations for the six factors were calculated. The original item scores for the six factors were averaged to create a composite score for each factor. Because logistic regression is sensitive to multicollinearity, it was diagnosed by examining the variance inflation factors (VIFs) and the condition indexes (CIs) for the predictor or predicator variables. The values for all of the VIFs were below the suggested threshold of 10. Tolerance values ranged from 0.62 (RA) to 0.98 (SZ), exceeding the recommended minimum of 0.1 . No condition index exceeded the threshold of 30 . The diagnostics for multicollinearity did not indicate the existence of multicollinearity among the predicator variables.

Cronbach's alpha was used for checking the reliability of the instrument's constructs. The Cronbach's alpha coefficient $(\alpha)$ for the scale as a whole was 0.804 . All of the six factors had an alpha value above 0.7, the lowest acceptable limit. Where appropriate, items where reverse coded.

\section{DATA ANALYSIS}

Logistic regression techniques were used to test support for the hypotheses proposed by the research or conceptual model. The goodness of fit of the logistic regression model was assessed with three different measures. First, the likelihood ratio test is an indicator to the strength of the relationship between the criterion variable and predictor variables for each regression. A small value for $-2 \log$ likelihood (-2LL) indicates a well-fitting model. The initial or null model -2LL, based on the mean of the criterion variable, was 110.908. With the six predictors, the -2LL for the research model was 75.068. The chi-square value indicates the improvement (reduction) in the -2LL value from the null model to the conceptual model. The chi-square value $\left(\chi^{2}=35.84, d f=6\right)$ was significant $(p<0.001)$. This indicates that there is a strong relationship between the criterion variable and the predictor variables. Second, the results of the Hosmer and Lemeshow goodness-of-fit test $\left(\chi^{2}=5.695, p=0.681\right)$ indicated that there are no differences between the fitted values and the actual values of the conceptual model. A $p<0.05$ is considered significant. The pseudo $R^{2}$ statistics, Cox and Snell $R^{2}(0.260)$ and Nagelkerke $R^{2}(0.429)$, are satisfactory in that approximately $43 \%$ of the data variation can be explained by the conceptual model. The results of the goodness-offit measures indicate a good fit between the conceptual model and the data.

Wald statistics were used to examine the significance of the regression coefficients in support of the hypothesized predicators. Three factors were significant at the 0.05 level: technical readiness $(p<0.001)$, institutional size $(p<$ $0.05)$, and complexity $(p<0.01)$. This means there is supporting evidence for the hypotheses $\mathrm{H} 5, \mathrm{H} 4$, and $\mathrm{H} 2$, respectively (see below). Relative advantage, regulatory policy, and service provider support were found to be nonsignificant discriminators. The sign of the regression coefficient $(\beta)$ indicates whether or not the predictor variable had a positive or negative effect on cloud computing adoption. All three factors (relative advantage, regulatory policy, and service provider support) were positively related to the likelihood of a college or university adopting cloud computing

The significance of the results of the logistic regression are presented for each hypothesis. Evidence is presented to support or reject each hypothesis.

$\mathrm{H}_{1}$ : Relative advantage is positively associated with cloud computing adoption. 
The regression coefficient for relative advantage $(\beta=0.244)$ was not found to be significant at the $p<0.01$ level. Relative advantage did not relate to the variance in the decisions of CIOs, IT directors, or IT managers at colleges and universities to adopt cloud computing.

$\mathrm{H}_{2}$ : Technical complexity is negatively associated with cloud computing adoption.

The regression coefficient for complexity $(\beta=0.972)$ was found to be significant at the $p<0.05$ level. Technical complexity did relate to the variance in the decisions of CIOs, IT directors, or IT managers at colleges and universities to adopt cloud computing.

$\mathrm{H}_{3}$ : Technical compatibility is positively associated with cloud computing adoption.

Measurement items related to compatibility were eliminated from the data analysis because of cross-loading or factor loadings below the threshold of 0.5. Compatibility was not a factor in the decisions of CIOs, IT directors, or IT managers at colleges and universities to adopt cloud computing.

$\mathrm{H}_{4}$ : Institutional size is positively associated with cloud computing adoption.

The regression coefficient for institutional size $(\beta=1.680)$ was found to be significant at the $\mathrm{p}<0.05$ level. Institutional size did relate to the variance in the decisions of CIOs, IT directors, or IT managers at colleges and universities to adopt cloud computing.

$\mathrm{H}_{5}$ : Technology readiness is positively associated with cloud computing adoption.

The regression coefficient for technology readiness $(\beta=1.406)$ was found to be significant at the $\mathrm{p}<0.001$ level. Technology readiness did relate to the variance in the decisions of CIOs, IT Directors, or IT Managers at colleges and universities to adopt cloud computing.

$\mathrm{H}_{6}$ : Perceived barriers are negatively associated with cloud computing adoption.

Measurement items related to perceived barriers were eliminated from the data analysis because of cross-loading or factor loadings below the threshold of 0.5. Perceived barriers was not a factor in the decisions of CIOs, IT directors, or IT managers at colleges and universities to adopt cloud computing.

$\mathrm{H}_{7}$ : Regulatory policy is negatively associated with cloud computing adoption.

The regression coefficient for regulatory policy $(\beta=-0.128)$ was found not to be significant at the $p<0.05$ level. Regulatory policy did relate to the variance in the decisions of CIOs, IT directors, or IT Managers at colleges and universities to adopt cloud computing.

$\mathrm{H}_{8}$ : Service provider support is positively associated with cloud computing adoption.

The regression coefficient for service provider support $(\beta=0.013)$ was found not to be significant at the $\mathrm{p}<0.05$ level. Service provider support did not relate to the variance in the decisions of CIOs, IT directors, or IT managers at colleges and universities to adopt cloud computing.

The research model correctly predicted $95.9 \%$ of the adopters and $38.1 \%$ of the non-adopters. The overall accuracy rate of the model was $85.7 \%$. Adoption of cloud computing by random choice would result in $(21 / 119)^{2}+(98 / 119)^{2}$ $=70.93 \%$. This is less than the overall rate predicted by the model; therefore, the logistic regression analysis was more accurate than random guessing in predicting cloud computing adoption.

\section{DISCUSSION}

The goal of this study was to identify the factors that determine the adoption or non-adoption of cloud computing by colleges and universities in the U.S. and Canada. The results of the study were interpreted in light of the theoretical 
research model. The model proposed relationships or linkages between technology, organization, and environmental factors and the decision of CIO, IT director, or IT manager at a college or university to adopt cloud computing.

The authors examined the effects the predictor variables of the technology context (relative advantage, complexity), the organization context (institutional size, technology readiness), and the environmental context (regulatory policy, service provider support) had on the criterion variable, cloud computing adoption. The results of the study indicate there are three determinants of cloud computing adoption: technology readiness, institutional size, and complexity. One factor was related to the technology context (complexity) and two factors were related to the organization context (technology readiness, institutional size).

\section{CONCLUSIONS}

This is the first study to examine the determinants of cloud computing adoption by colleges and universities. The determinants were found to be complexity, institutional size, and technology readiness in that they were able to distinguish between adopters and non-adopters of cloud computing. Five factors were found to be insignificant determinants: relative advantage, compatibility, perceived barriers, regulatory policy, and service provider support. Understanding the effects of these factors can guide CIOs, IT director, and IT managers in their decisions to adopt cloud computing at their institutions.

This study also has implications for the service providers of cloud computing resources and services. Large institutions have more financial and employee resources available to research, evaluate, and implement the products offered by cloud computing vendors. With more institutional resources at their disposal, larger institutions are in a position to manage the complexities associated with cloud computing adoption. Smaller institutions may only be in a position to adopt a single cloud solution, such as e-mail. Larger institutions can consider a wider range of products and services, such as online collaboration or conferencing tools and learning management systems.

\section{REFERENCES}

1. Aaron, L. S., \& Roche, C. M. (2012). Teaching, learning, and collaborating in the cloud: Applications of cloud computing for educators in post-secondary institutions. Journal of Educational Technology Systems, 40(2), 95111.

2. Abokhodair, N., Taylor, H., Hasegawa, J., \& Mowery, S. J. (2012). Heading for the clouds? Implications for cloud computing adopters. AMCIS 2012 Proceedings (Paper 6).

3. Aldrich, A. W. (2010). Universities and libraries move to the mobile web. EDUCAUSE Quarterly, 33(2). Retrieved from http://www.educause.edu/EDUCAUSE+Quarterly/EDUCAUSEQuarterlyMagazineVolum/UniversitiesandLibr ariesMoveto/206531

4. Al-Zoube, M., El-Seoud, S., \& Wyne, M. F. (2010). Cloud computing based e-learning system. International Journal of Distance Education Technologies, 8(2), 58-71. http://dx.doi.org/10.4018/jdet.2010040105

5. Behrend, T. S., Wiebe, E. N., London, J. E., \& Johnson, E. C. (2011). Cloud computing adoption and usage in community colleges. Behaviour \& Information Technology, 30(2), 231-240. http://dx.doi.org/10.1080/0144929X.2010.489118

6. Bernius, S., \& Krönung, J. (2012). Fostering academic research by cloud computing: The users' perspective. ECIS 2012 Proceedings (Paper 181). Retrieved from http://aisel.aisnet.org/ecis2012/181

7. Blue, E., and Tirotta, R. (2011). The benefits \& drawbacks of integrating: Cloud computing and interactive whiteboards in teacher preparation. TechTrends, 55(3), 31-38.

8. Cahill, J.L. (2011). The collaborative benefits of Google Apps Education Edition in higher education (Doctoral dissertation). Available from ProQuest Dissertations and Theses database. (UMI No. 919708594).

9. Calvo, R. A., O’Rourke, S. T., Jones, J., Yacef, K., \& Reimann, P. (2011). Collaborative writing support tools on the cloud. IEEE Transaction on Learning Technologies, 4(1), 88-97.

10. Chebrolu, S. B. (2010). Assessing the relationships among cloud adoption, strategic alignment and information technology effectiveness (Doctoral dissertation). Available from ProQuest Dissertations and Theses database. (UMI No. 762321386) 
11. Chong, A. Y., Ooi, K., Lin, B., \& Raman, M. (2009). Factors affecting the adoption level of c-commerce: An empirical study. The Journal of Computer Information Systems, 50(2), 13-22.

12. Crawford, D., Angers., M, \& Dunington, B. (2015). EduCloud - Low-cost, On-demand Servers for Higher Education. BCNET Conference 2015, Vancouver, BC, Canada. Retrieved from https://www.bc.net/educloudserver-low-cost-demand-servers-higher-education

13. Denton, D. W. (2012). Enhancing instruction through constructivism, cooperative learning, and cloud computing. Techtrends: Linking Research and Practice to Improve Learning, 56(4), 34-41.

14. Doelitzscher, F., Sulistio, A., Reich, C., Kuijs, H., \& Wolf, D. (2011). Private cloud for collaboration and elearning services: From IaaS to SaaS. Computing, 91(1), 23-42. http://dx.doi.org/10.1007/s00607-010-0106-z

15. Dwivedi, Y.K., \& Mustafee, N. (2010). It's unwritten in the Cloud: the technology enablers for realising the promise of Cloud Computing, Journal of Enterprise Information Management, 23(6), 673 - 679.

16. Flinders, K. (2011, February 1). University of Salford makes $£ 5.7 \mathrm{~m}$ cloud computing investment. ComputerWeekly.com

17. Goel, M., Kiran, D., \& Garg, D. (2011). Impact of cloud computing on ERP implementations in higher education. International Journal of Advanced Computer Science \& Applications, 2(6), 146.

18. Gray, T. (2010). A tale of two clouds. EDUCAUSE Quarterly, 33(2). Retrieved from http://www.educause.edu/EDUCAUSE+Quarterly/EDUCAUSEQuarterlyMagazineVolum/ATaleofTwoClouds/2 06529

19. Hoberg, P., Wollersheim, J., \& Krcmar, H. (2012). The Business Perspective on Cloud Computing - A Literature Review of Research on Cloud Computing. AMCIS 2012 Proceedings (Paper 5).

20. Information Age. (2011, February 7). Universities to share £12.m cloud services in England. Retrieved from http://www.information-age.com/channels/it-services/news/1599748/universities-to-share-125m-cloudservices.thtml

21. Janssen, M., \& Joha, A. (2011). Challenges for adopting cloud-based software as a service (SaaS) in the public sector. ECIS 2011 Proceedings (Paper 80).

22. Katz, R.N., Goldstein, P.J., \& Yanosky, R. (2009). Demystifying cloud computing for higher education. EDUCAUSE Quarterly, 33(2). Retrieved from http://net.educause.edu/ir/library/pdf/ERB1004.pdf

23. Katzan, H. (2010). The education value of cloud computing. Contemporary Issues in Education Research, 3(7), $37-42$.

24. Laisheng, X., \& Zhengxia, W. (2011). Cloud computing: A new paradigm for e-learning. Proceedings of the 2011 Third International Conference on Measuring Technology and Mechatronics Automation, IEEE Computing Society, Washington, DC, USA. http://dx.doi.org/10.1109/ICMTMA.2011.181

25. Li, P., \& Toderick, L. W. (2010). Cloud in cloud: Approaches and implementations. Proceedings of the 2010 ACM conference on Information Technology Education, USA, 105-110. http://dx.doi.org/10.1145/1867651.1867678

26. Li, Y., \& Chang, K. (2012). A study on user acceptance of cloud computing: A multi-theoretical perspective. AMCIS 2012 Proceedings (Paper 19).

27. Lin, H., \& Lin, S. (2008). Determinants of e-business diffusion: A test of the technology diffusion perspective. Technovation, 28(3), 135-145. http://dx.doi.org/10.1016/j.technovation.2007.10.003.

28. Low, C., Chen, Y., \& Wu, M. (2011). Understanding the determinants of cloud computing adoption. Industrial Management + Data Systems, 111(7), 1006-1023. http://dx.doi.org/10.1108/02635571111161262

29. Masud, A.H., Huang, X., \& Yong, J. (2012). Cloud computing for higher education: A roadmap. Proceedings of the 2012 IEEE 16th International Conference on Computer Supported Cooperative Work in Design, China, 552-557.

30. Microsoft. (2010, December 21). State University of New York moves to Microsoft's cloud. Microsoft News Center. Retrieved from http://www.microsoft.com/en-us/news/press/2010/dec10/12-21 sunypr.aspx

31. Mircea, M., \& Andreescu, A.I. (2011). Using cloud computing in higher education: A strategy to improve agility in the current financial crisis. Communications of the IBIMA, 2011, Article ID 875547, 1-14. http://dx.doi.org/10.5171/2011.875547

32. Oliveira, T., \& Martins, M. (2010). Firms patterns of e-business adoption: Evidence for the European Union-27. Electronic Journal of Information Systems Evaluation, 13(1), 47-55.

33. Pan, M., \& Jang, W. (2008). Determinants of the adoption of enterprise resource planning within the technology-organization-environment framework: Taiwan's communications industry. The Journal of Computer Information Systems, 48(3), 94-102.

http://search.proquest.com/docview/232585669?accountid=28180 


\section{Issues in Information Systems}

Volume 16, Issue III, pp. 1-10, 2015

34. Park, S., \& Ryoo, S. (2012). An empirical investigation of end-users' switching toward cloud computing: A two factor theory perspective. Computers in Human Behavior, 29(1), 160-170.

35. Powelson, S. E. (2012). An examination of small businesses' propensity to adopt cloud computing innovation. (Doctoral dissertation). Available from ProQuest Dissertations and Theses database. (UMI No. 963525817).

36. Praveena, K. \& Betsy, T. (2009). Application of cloud computing in academia. The IUP Journal of Systems Management, 7(3), 50-54.

37. Rao, N.M, Sasidhar, C., \& Kumar, V. S. (2010). Cloud computing through mobile-learning. International Journal of Advanced Computer Science and Applications, 1(6), 42 - 47. Retrieved from http://thesai.org/Downloads/Volume1No6/Paper_7_Cloud_Computing_Through_Mobile-Learning.pdf

38. Ratten, V. (2012). Entrepreneurial and ethical adoption behaviour of cloud computing. Journal of High Technology Management Research, 23(2), 155-164.

39. Rogers, E.M. (2003). Diffusion of innovations ( $5^{\text {th }}$ ed.). New York, NY: The Free Press.

40. Round, K. (2011). E-learning 2.0: Cloud computing and the online learner. Journal of Applied Learning Technology, 1(4), 24-27.

41. Sarkar, P. \& Young, L. (2011). Sailing the cloud: A case study of perceptions and changing roles in an Australian university. ECIS 2011 Proceedings (Paper 124).

42. Saya, S., Pee, L.G., \& Kankanhalli, A. (2010). The impact of institutional influences on perceived technological characteristics and real options in cloud computing adoption. ICIS 2010 Proceedings (Paper 24).

43. Scale, M. E. (2010). Assessing the impact of cloud computing and web collaboration on the work of distance library services. Journal of Library Administration, 50(7/8), 933-950. http://dx.doi.org/10.1080/01930826.2010.488995

44. Schaffer, H.E, Averitt, S.F., Holt, M.I., Peeler, A., Sills, E.D. \& Vouk, M.A. (2009). NCSU's virtual computing lab: A cloud computing solution. Computing, 42(7), 94-97.

45. Seay, C. \& Tucker, G. (2010). Virtual computing initiative at a small public university. Communications of the $A C M$, 53(3), 75-83. http://dx.doi.org/10.1145/1666420.1666441

46. Sheard, R. (2010). Innovating in the cloud: Exploring cloud computing to solve IT challenges. EDUCAUSE Quarterly, 33(2). Retrieved from

http://www.educause.edu/EDUCAUSE+Quarterly/EDUCAUSEQuarterlyMagazineVolum/InnovatingintheClou dExploringC/206530

47. Siegle, D. (2010). Cloud computing: A free technology option to promote collaborative learning. Gifted Child Today, 33(4), 41-45.

48. Stankov, I., Miroshnychenko, Y., \& Kurbel, K. (2012). Cloud computing adoption in German Internet start-up companies. BLED 2012 Proceedings (Paper 37).

49. Sultan, N. (2011). Reaching for the "cloud": How SMEs can manage. International Journal of Information Management, 31(3), 272-278. http://dx.doi.org/10.1016/j.ijinfomgt.2010.08.001

50. Tan, K. S., Chong, S. C., Ling, B., \& Eze, U. C. (2009). Internet-based ICT adoption: Evidence from Malaysian SMEs. Industrial Management + Data Systems, 109(2), 224-244.

51. Taylor, C.W., \& Hunsinger, D. S. (2011). A study of student use of cloud computing applications. Journal of Information Technology Management, 23(3), 36-50.

52. Thomas, P. (2011). Cloud computing: A potential paradigm for practising the scholarship of teaching and learning. Electronic Library, 29(2), 214-224.

53. To, M. L., \& Ngai, E.W.T. (2006). Predicting the organisational adoption of B2C e-commerce: An empirical study. Industrial Management + Data Systems, 106(8), 1133-1147. http://dx.doi.org/10.1108/02635570610710791

54. Tornatzky, L. G., \& Fleischer, M. (1990). The processes of technological innovation. Lexington, MA: Lexington Books.

55. Tornatzky, L. G., \& Klein, K. J. (1982). Innovation characteristics and innovation adoption implementation: A meta-analysis of findings. IEEE Transactions on Engineering Management, EM-29(1), 28-45.

56. Truong, H., \& Dustdar, S. (2011). Cloud computing for small research groups in computational science and engineering: current status and outlook. Computing, 91(1), 75-91. http://dx.doi.org/10.1007/s00607-010-0120-1

57. Tweel, A. (2012). Examining the relationship between technological, organizational, and environmental factors and cloud computing adoption (Doctoral dissertation). Available from ProQuest Dissertations and Theses database. 


\section{Issues in Information Systems}

Volume 16, Issue III, pp. 1-10, 2015

58. Ulf, M., Sarkar, P.K., \& Young, L.W. (2012). Looking through the clouds: A tale of two universities. PACIS 2012 Proceedings (Paper 120).

59. Vishwakarma, A. K., \& Narayanan, A. E. (2012). E-learning as a service: A new era for academic cloud approach. First International Conference on Recent Advances in Information Technology, India.

60. Vouk, M. (2008). Cloud computing -- issues, research and implementations. Journal of Computing \& Information Technology, 16(4), 235-246. http://dx.doi.org/10.2498/cit.1001391

61. Zhu, K., Kraemer, K. L., \& Xu, S. (2006). The process of innovaion assimilation by firms in different countries: A technology diffusion perspective on e-business. Management Science, 52(10), 1557-1576. 